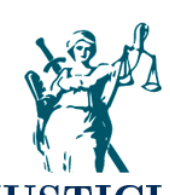

JUSTICIA

ISSN impreso 0124-744

\title{
La función de reinserción social y el papel de los jueces de ejecución de penas y medidas de seguridad en Colombia ${ }^{1}$
}

\section{The role of social reintegration and the role of judges in the enforcement of penalties and security measures in Colombia}

\author{
Patricia Guzman González \\ Corporación Universitaria del Caribe Cecar, Colombia \\ patricia.guzman@cecar.edu.co \\ Jaime Rambao Hernández \\ Corporación Universitaria del Caribe Cecar, Colombia \\ jaime.rambaoh@cecar.edu.co
}

Recibido: 15 de marzo de 2018 / Aceptado: 9 de septiembre de 2018

https://doi.org/10.17081/just.24.35.3398

\section{Resumen}

Este artículo de investigación responde a los alcances parciales del objetivo específico "analizar atendiendo al nuevo rol del juez de ejecución de penas y medidas de seguridad como ejercen el seguimiento al cumplimiento de la reinserción social del condenado" dentro del proyecto "Reinserción Social en el caribe colombiano. Un estudio de caso en la Penitenciaría El Bosque de Barranquilla y la Cárcel La Vega de Sincelejo durante los años 2013-2017"

Palabras Clave: Función de la pena, reinserción social, juez de ejecución de penas y medidas de seguridad, condenado.

\section{Abstract}

This research article responds to the scope of the specific objective "to analyze the new role of the judge of execution of sentences and security measures as they exercise the follow-up to the fulfillment of the social reintegration of the condemned" within the project "Social Reinsertion in the Colombian Caribbean. A case study at El Bosque de Barranquilla Penitentiary and La Vega Prison in Sincelejo during the years 2013-2017.

Keywords: Function of the penalty, social reinsertion, judge of execution of sentences and security measures, convicted.

\section{Como citar:}

Guzman González, P., \& Rambao Hernández, J. (2019). La función de reinserción social y el papel de los jueces de ejecución de penas y medidas de seguridad en Colombia. Justicia, 24(35). 133-148. https://doi.org/10.17081/just.24.35.3398

I Artículo de investigación financiado par la Corparación Universitaria del Caribe Cecar, Universidad Simón Balívar y Universidad del Atlántica.

Justicia Vol. No. 35: pp. 133-148. Enero-Junio, 2019. DOI: 10.17081/just.24.35.3398

CCopyright 2019 by Autores

open 2 access (c) (1) 


\section{INTRODUCCIÓN}

Desde los resultados del proyecto financiado por Colciencias titulado "Perspectiva psicojurídica del incesto en la Región Caribe" adelantado desde el Grupo "Violencia, criminalidad y familia en la costa Caribe colombiana" de la Universidad Simón Bolívar, se encontró que la función de reinserción social en su implementación por parte del INPEC no se está cumpliendo acorde a los parámetros establecidos desde los instrumentos internacionales, en especial lo contemplado en las reglas mínimas de tratamiento de los reclusos y lo establecido en el Código Penitenciario y Carcelario, de ahí también se pudo concluir que el Juez de Ejecución de Penas y medidas de seguridad también juega un rol importantísimo para el cumplimiento de las funciones de la pena (Guzmán, 2014).

De acuerdo a lo anterior, el sistema de ejecución de penas colombiano se encuentra en cuidados intensivos y ello se evidencia por la crisis carcelaria en que se encuentra hoy en día el país porque el procesado y condenado son con frecuencia víctima de violaciones en materia de Derechos Humanos donde el hacinamiento y las condiciones de indignidad, afectan todas las garantías que el Estado debe brindar al recluido en los centros carcelarios y penitenciarios por estar en condiciones de inferioridad siendo sujeto de protección especial por parte del Estado, aunado a otros factores que están incidiendo notoriamente en el tratamiento penitenciario eficaz.

Por ello se hizo necesario abordar desde el proyecto "Reinserción Social en el caribe colombiano. Un estudio de caso en la Penitenciaría El Bosque de Barranquilla y la Cárcel La Vega de Sincelejo durante los años 2013-2017" analizar la manera cómo se aplica o implementa la política de reinserción social en dos centros carcelarios y penitenciarios del país, en este caso en la Penitenciaría El Bosque de Barranquilla y La Vega de Sincelejo y el compromiso de cada uno de los actores responsables de ese proceso, entre ellos el del juez de ejecución de penas y medidas de seguridad de la ciudad de Barranquilla.

El Juez de ejecución de penas y medidas de seguridad es un actor importantísimo para el cumplimiento de la función de reinserción social. Pues por mandato legal debe estar en permanente seguimiento a la ejecución de la pena de los condenados y las condiciones en las que éstos se encuentran para el efectivo cumplimiento de la misma.

1.1. El rol del juez de ejecución de penas y medidas de seguridad frente al proceso de reinserción social.

La ejecución de la pena, una vez culminado el proceso penal, deja al juez de conocimiento dar paso a la competencia del Juez de ejecución de penas y medidas de seguridad como garante de la protección de los Derechos Humanos de los condenados, funciones que están bien establecidas en la norma (Código de Procedimiento Penal y Código Penitenciario y Carcelario) que deben ser cumplidas en total armonía con los funcionarios del Instituto Nacional Penitenciario y Carcelario (INPEC). El individuo aun estando sentenciado sigue siendo un sujeto de derechos, y como regla general con la función que tiene el juez de ejecución de penas se deberían minimizar los abusos y arbitrariedades que se cometen en contra del interno, ya que el juez de ejecución de penas y medidas de seguridad se convierte en un vigilante y garante de los derechos de los que goza un condenado atendiendo a las facultades que le reconoce la Constitución, los tratados internacionales y las leyes, así mismo el individuo tendrá en el juez una instancia para defenderse 
de un posible atropello que se pudiera cometer en su contra por parte de funcionarios del INPEC e invocar cualquier incidente a su favor.

\subsection{Origen y funciones de los jueces de ejecución de penas y medidas de seguridad en Colombia.}

El artículo 1 de la Constitución de Colombia de 1991, que declara que Colombia es un Estado democrático y social de derecho fundado en el respeto a la dignidad humana y a su vez, el artículo 29 de la misma, expresa el derecho al debido proceso y a un juez natural encargado de velar por su cumplimiento, nace entonces, al tratarse lo concerniente a los derechos fundamentales y su protección por parte del Estado, entre los que se incluyen a las personas privadas de la libertad, nace la figura de los Jueces de Ejecución de Penas y Medidas de Seguridad.

Con base en esta Constitución se expide el Código Penitenciario y Carcelario (Ley 65 de 1993), el cual dedicó su Título $\mathrm{V}$ al Juez de ejecución de Penas y Medidas de Seguridad. Antes de esta normativa en materia penitenciaria y carcelaria que destaca el rol del juez de ejecución de penas y medidas de seguridad, en nuestro ordenamiento jurídico penal en el sistema inquisitivo es el mismo Juez de conocimiento quien profería la sentencia de condena y además debía encargarse de su ejecución.

Nace la figura de los jueces de ejecución de penas y medidas de seguridad en Colombia, por cuanto al Juez de Conocimiento al tener además que supervisar la ejecución de la sentencia, a la hora de hacer control al proceso de ejecución en cuanto a redenciones de pena, permisos, posibilidades de libertad condicional y libertades por pena cumplida, ya que el penado, podría estar en cualquier cárcel del país y no importando que lejos estuviera ésta, a el Juez de conocimiento le correspondía tomar las decisiones, en la mayoría de los casos con muchos atrasos a efectos de hacer llegar las comunicaciones al penado y por ello muchos penados pagaban más de las penas impuestas mientras que llegaban las comunicaciones de libertad incluso por pena físicamente cumplida, se reparten funciones, quedando, entonces consignadas las funciones de éstos últimos, consagradas en el código de procedimiento penal y código penitenciario y carcelario (En:http://www.terragnijurista.com.ar/doctrina/juez.htm).

El Código de Procedimiento Penal Colombiano, establece en su artículo 38 las funciones de los jueces de ejecución de penas y medidas de seguridad, así:

"Artículo 38. De los jueces de ejecución de penas y medidas de seguridad. Los jueces de ejecución de penas y medidas de seguridad conocen:

1. De las decisiones necesarias para que las sentencias ejecutoriadas que impongan sanciones penales se cumplan.

2. De la acumulación jurídica de penas en caso de varias sentencias condenatorias proferidas en procesos distintos contra la misma persona.

3. Sobre la libertad condicional y su revocatoria.

4. De lo relacionado con la rebaja de la pena y redención de pena por trabajo, estudio o enseñanza.

5. De la aprobación previa de las propuestas que formulen las autoridades penitenciarias o de las solicitudes de reconocimiento de beneficios 
administrativos que supongan una modificación en las condiciones de cumplimiento de la condena o una reducción del tiempo de privación efectiva de libertad.

6. De la verificación del lugar y condiciones en que se deba cumplir la pena o la medida de seguridad. Asimismo, del control para exigir los correctivos o imponerlos si se desatienden, y la forma como se cumplen las medidas de seguridad impuestas a los inimputables.

En ejercicio de esta función, participarán con los gerentes o directores de los centros de rehabilitación en todo lo concerniente a los condenados inimputables y ordenará la modificación o cesación de las respectivas medidas, de acuerdo con los informes suministrados por los equipos terapéuticos responsables del cuidado, tratamiento y rehabilitación de estas personas. Si lo estima conveniente podrá ordenar las verificaciones de rigor acudiendo a colaboraciones oficiales o privadas.

7. De la aplicación del principio de favorabilidad cuando debido a una ley posterior hubiere lugar a reducción, modificación, sustitución, suspensión o extinción de la sanción penal.

8. De la extinción de la sanción penal.

9. Del reconocimiento de la ineficacia de la sentencia condenatoria cuando la norma incriminadora haya sido declarada inexequible o haya perdido su vigencia.

Parágrafo. Cuando se trate de condenados que gocen de fuero constitucional o legal, la competencia para la ejecución de las sanciones penales corresponderá, en primera instancia, a los jueces de ejecución de penas y medidas de seguridad del lugar donde se encuentre cumpliendo la pena. La segunda instancia corresponderá al respectivo juez de conocimiento.

Parágrafo 2o. [Parágrafo adicionado por el artículo 1 de la Ley 937 de 2004. El nuevo texto es el siguiente:] Los jueces penales del circuito y penales municipales conocerán y decretarán la extinción de la sanción penal por prescripción en los procesos de su competencia.

En atención a lo anterior, si bien de manera taxativa, la norma no establece que una de las funciones de los jueces de ejecución de penas y medidas de seguridad, es el seguimiento al cumplimiento de las funciones de la pena, entre ellas la de reinserción social, los numerales 4,5 y 6 de este artículo como consecuencia de lo atinente a "la rebaja de la pena y redención de pena por trabajo, estudio o enseñanza", ineludiblemente tiene que ver con el seguimiento que el juez debe hacer al desarrollo y cumplimiento de las actividades que involucran en el tratamiento penitenciario lo que conceptualmente tiene que ver con el proceso de reinserción social que debe convertir a los condenados en mejores seres humanos y seres productivos, y ello no se consigue sin el estudio, el trabajo y la formación en valores, tratamiento psicosocial.

Para que el juez haga su tasación para la redención debe previamente vigilar el grado de participación del condenado en estas actividades y su resultado. De igual manera en este proceso cuenta la buena conducta del condenado y su valoración psicológica. Valga la pena traer a colación el símil del profesor con su estudiante al cual debe evaluar su proceso de aprendizaje desde que lo toma al iniciar su cátedra hasta finalizarla, así de todo ese proceso el profesor evalúa al 
estudiante con una nota que corresponde a su aprobación o reprobación de su materia. Si nos trasladamos al verdadero rol que debe tener el juez para redención de penas equivale a un proceso similar.

Ahora bien, en lo que corresponde a la función:

"De la aprobación previa de las propuestas que formulen las autoridades penitenciarias o de las solicitudes de reconocimiento de beneficios administrativos que supongan una modificación en las condiciones de cumplimiento de la condena o una reducción del tiempo de privación efectiva de libertad",

al igual que la anterior, tiene aplicabilidad la participación activa que debe tener el juez de ejecución de penas en el proceso de reinserción social, toda vez que si se cumple lo anterior en excelentes condiciones se evalúa la posibilidad de recibir los beneficios administrativos reconocidos por la ley.

Y la función que complementa la obligatoriedad del Juez de hacer seguimiento al cumplimiento de las funciones de la pena viene dado de la interpretación que deba dársele a la función:

"De la verificación del lugar y condiciones en que se deba cumplir la pena o la medida de seguridad. Asimismo, del control para exigir los correctivos o imponerlos si se desatienden, y la forma como se cumplen las medidas de seguridad impuestas a los inimputables".

No cabe duda que al momento de evaluar las condiciones y el lugar donde el condenado deba cumplir la pena, toca todos los aspectos de las condiciones de infraestructura, salubridad, sitios deportivos, sitios de trabajo, sitios de estudio, como también la manera como son llevados los procesos para que cada uno se dé eficazmente.

Por lo anterior el rol del juez de ejecución de penas y medidas de seguridad es activo (Rodríguez; Hernández \& Tuirán, 2010) y no pasivo, ya que para hacer seguimiento al cumplimiento de la sanción penal debe realizar visitas periódicas a los establecimientos de reclusión que le sean asignados.

Así como en el proceso penal se encuentra el principio de la inmediación de la prueba (Rodríguez, \& Guzmán. 2009), en materia penitenciaria y carcelaria está la inmediación del juez sobre la ejecución de la pena. Frente al grave problema del hacinamiento carcelario, donde existe sobre población teniendo en cuenta que la misma está determinada no por el número de condenados que es menor a la cifra de procesados que hay, los jueces de ejecución de penas resultan ser insuficientes para ejercer su rol tal cual como la norma lo prescribe.

Por tanto, gran parte de sus funciones con relación al cumplimiento de las funciones de la pena y ejecución de la pena, son trasladadas a los funcionarios del Instituto Nacional Penitenciario y Carcelario INPEC, específicamente al encargado del tratamiento penitenciario. Limitándose entonces los jueces de ejecución de penas a resolver peticiones únicamente relacionadas con redenciones de la pena, de libertad, entre otras (Funciones de decisión, no de control y vigilancia a las funciones de la pena). Con relación a ello, las visitas que deben realizar a las cárceles y penitenciarías no son tan frecuentes.

Como se puede observar, de plano resulta entonces aplicada de manera irregular el proceso de reinserción social que debe ser vigilado por los jueces de ejecución de penas en articulación con el INPEC. 
Para que los jueces de ejecución de penas y medidas de seguridad puedan comprender su competencia y funciones, la Sala Penal de la Corte Suprema de Justicia (Auto AP-83122016 (49271), Nov. 30/16) ha explicado que la competencia de los jueces de conocimiento ha de restringirse a la de tramitar los procesos penales sin que tengan injerencia alguna, por regla general, en la ejecución y vigilancia de las sanciones que se impongan.

Este pronunciamiento de esta Alta Corte hace que recobre valor la relevancia del factor personal que acompaña al condenado en este contexto y lo vincula de manera inevitable con los fines o funciones de la pena. En esta jurisprudencia se fijan tres reglas con respecto a este factor, así:

"Primera regla. Cuando el sentenciado se encuentra privado de la libertad, la vigilancia de la sanción corresponderá al juez de ejecución de penas del lugar donde se encuentra ubicado el centro penitenciario.

Ello al margen de que confluyan simultáneamente otros fallos condenatorios en su contra en los que se haya ordenado su cumplimiento intramural o concedido un subrogado penal, lo cual también aplica si el condenado está en prisión domiciliaria

Segunda regla. Si el sentenciado se ha hecho acreedor de un subrogado penal, es decir, se encuentra en libertad, la vigilancia del periodo de prueba será del juez de ejecución de penas de la circunscripción territorial del despacho que profirió el fallo condenatorio.

$Y$ en el evento de que en el lugar aún no hayan sido creados dichos despachos, la competencia recaerá en un funcionario de la misma categoría y especialidad con sede en la ciudad cabecera del respectivo circuito penitenciario.

Desde esta perspectiva, la Sala dice que se afianza la tesis respecto a que han de ser estos mismos funcionarios, no los juzgadores de primera instancia, los convocados a asumir la vigilancia de la ejecución de la condena.

Tercera regla. Vale la pena decir que en esta conceptualización se incluyen aquellos casos en los cuales por situaciones individuales, justificadas y razonables los condenados que se encuentran en libertad no puedan concurrir a los lugares en los que se encuentran emplazados estos despachos.

En esos eventos se puede contemplar, de forma excepcional, la opción de comisionar en temáticas que lo permitan y que no impliquen transmisión de competencias a los jueces municipales con asiento en las localidades donde no hagan presencia los jueces de ejecución para el seguimiento del periodo de prueba.

En México, existen también estos jueces y llama poderosamente la atención que entre sus funciones se encuentra de manera expresa: "Hacer las recomendaciones necesarias para que estos centros cumplan con los fines de la reinserción social". El modelo de reinserción consiste en las acciones y estrategias que buscan la reinserción social de los sentenciados, a través de tratamientos y programas con base en el trabajo, la capacitación para él mismo, la educación, la salud y el deporte, así como del seguimiento y vigilancia de los preliberados.

Los principios rectores en la ejecución de sanciones son: Legalidad, trato humano, inmediación, dignidad, jurisdiccionalidad, confidencialidad, igualdad, celeridad y oportunidad. Derechos de los internos (sentenciados y procesados).-Recibir un trato humano y los medios de salud, educativos, laborales, sociales, recreativos y deportivos para su reinserción a la sociedad. (Recuperado En: https://www.quadratin.com.mx/sucesos/Funcion-del-juez-de-ejecucion-de-sanciones-en-Nuevo- 
Sistema-de-Justicia/).

De todo lo anterior se desprende que el rol del juez de ejecución de penas y medidas de seguridad, casi que en todos los países latinoamericanos, en especial en el nuestro, no solo tiene una función garante sino social en el proceso de reinserción social ya que su compromiso va más allá de tener en cuenta los aspectos relacionados con solicitudes que hagan los condenados y resolverlas, sino en el sentido de que debe velar por el cumplimiento de la finalidad última de la pena que se convierte en la principal de las funciones que es la de "resocializar y reeducar" a quien comete un delito para que una vez cumpla con la pena impuesta por el Estado regrese o se reincorpore nuevamente a la sociedad como mejor ser humano, y es este Juez que por mandato legal está revestido de ese poder que lo faculta para el seguimiento a la construcción de ese nuevo ser humano.

De ahí la función importantísima de este juez, de vigilar y controlar la ejecución de lo que establece una sentencia, de garantizar el respeto de los demás derechos que le asisten al condenado y de evitarle al penado un doble estado de victimización. El juez de ejecución de penas, entre sus otras funciones, tiene la obligación de construir un nuevo ciudadano, formado con principios y valores a través de todo un proceso de conversión espiritual, apoyo psicológico, social, para que a través del tratamiento penitenciario el condenado presente signo de progreso con relación a su comportamiento que dio origen a la sanción y en consecuencia devolverlo como bueno a la sociedad. (Recuperado En:http://m.monografias.com/trabajos29/juez-ejecucionpenal/juez-ejecucion-penal.shtml).

1.3. Procedimiento para el cumplimiento de la reinserción social atendiendo a las funciones de los jueces de ejecución de penas y medidas de seguridad.

De acuerdo a lo que preceptúa el Código de Procedimiento Penal y Código Penitenciario y Carcelario de nuestro país, le corresponde a los Jueces de Ejecución de penas vigilar las condiciones en las que se deba cumplir la pena al interior de las cárceles y penitenciarías. Este procedimiento está dado por lo expresado, en primer lugar, por los artículos 9 y 10 de la ley 65 de 1993, así:

"Artículo 9o. Funciones y Finalidad de la Pena y de las Medidas de Seguridad. La pena tiene función protectora y preventiva, pero su fin fundamental es la resocialización. Las medidas de seguridad persiguen fines de curación, tutela y rehabilitación.

Artículo 10. Finalidad del Tratamiento Penitenciario. El tratamiento penitenciario tiene la finalidad de alcanzar la resocialización del infractor de la ley penal, mediante el examen de su personalidad y a través de la disciplina, el trabajo, el estudio, la formación espiritual, la cultura, el deporte y la recreación bajo un espíritu humano y solidario".

En su título V, artículo 51 nos habla del Juez de Ejecución de Penas y Medidas de Seguridad, el cual:

"garantizará la legalidad en la ejecución de la sanción penal y, en ejercicio de su facultad de ejecución de las sentencias proferidas por los Jueces Penales, conoce: 1. Del cumplimiento de las normas contenidas en este Código y en 
especial de sus principios rectores. 2. De todo lo relacionado con la libertad del condenado que deba otorgarse con posterioridad a la sentencia, rebaja de penas, redención de pena por trabajo, estudio o enseñanza y extinción de la condena. 3. De la verificación del lugar y condiciones en que se deba cumplir la pena o la medida de seguridad. 4. De la acumulación jurídica de penas en concurso de varias sentencias condenatorias proferidas en procesos distintos contra la misma persona. 5. De la aplicación del principio de favorabilidad cuando debido a una ley posterior, hubiese lugar a reducción o extinción de la pena. 6. Del reconocimiento de la ineficacia de la sentencia condenatoria cuando la norma discriminadora haya sido declarada inexequible o haya perdido su vigencia. 7. Del aporte de pruebas para el esclarecimiento de los hechos punibles cometidos en los centros de reclusión a fin de que sean investigados por las autoridades competentes."

Los Jueces de ejecución de penas y medidas de seguridad por tanto deben velar y garantizar porque la pena cumpla con sus funciones de la manera correcta, según la reforma a esta ley, mediante la 1709 de 2014, así:

"Artículo 7A. Obligaciones especiales de los Jueces de Penas y Medidas de Seguridad. Los Jueces de Penas y Medidas de Seguridad tienen el deber de vigilar las condiciones de ejecución de la pena y de las medidas de seguridad impuesta en la sentencia condenatoria.

Los Jueces de Ejecución de Penas y Medidas de Seguridad, de oficio o a petición de la persona privada de la libertad o su apoderado de la defensoría pública o de la Procuraduría General de la Nación, también deberán reconocer los mecanismos alternativos o sustitutivos de la pena de prisión que resulten procedentes cuando verifiquen el cumplimiento de los respectivos requisitos".

En estos artículos se refleja el papel activo que debe tener el juez de ejecución de penas en especial en el proceso de reinserción social como fin esencial de la pena. Ellos mediante visitas periódicas que deben realizar con cierta frecuencia a las cárceles para verificar precisamente las condiciones en las que se encuentran los condenados en cumplimiento de sus penas, deben minimamente entrar en contacto directo con los condenados a fin de corroborar tales condiciones y la manera como es llevado su tratamiento penitenciario recibido por parte de funcionarios del INPEC. Si bien ellos son los que permanecen con los condenados, el juez de ejecución de penas no pierde facultades en este proceso, otra cosa es que esta labor deba realizarse de manera articulada con ellos. EI INPEC debe rendir informes a estos jueces a fin de frente a las solicitudes de los condenados para acceder a sus beneficios administrativos y redenciones por estudio y trabajo, el juez pueda decidir.

En este procedimiento parece que el juez solo se centra, ya que de manera explícita la norma no lo contempla pero ello se desprende de la interpretación extensiva del articulado que le atribuye en sus funciones lo relacionado al cumplimiento de la ejecución de la pena, en donde si claramente está establecido es la "reinserción social" por tanto el juez como consecuencia debe vigilar y hacer seguimiento a que ésta se cumpla a través del tratamiento penitenciario realizado por el INPEC.

1.4. Mirada desde el ejercicio profesional del abogado respecto de la función del juez de ejecución de penas y medidas de seguridad en barranquilla. 
Se realizó una encuesta a 11 abogados litigantes en Derecho Penal en Barranquilla, escogidos de manera aleatoria. El cuestionario contó con ocho preguntas atinentes al objeto de estudio, se muestra una gráfica por respuestas dadas a cada pregunta y seguidamente una breve interpretación de los resultados en cada una de ellas:

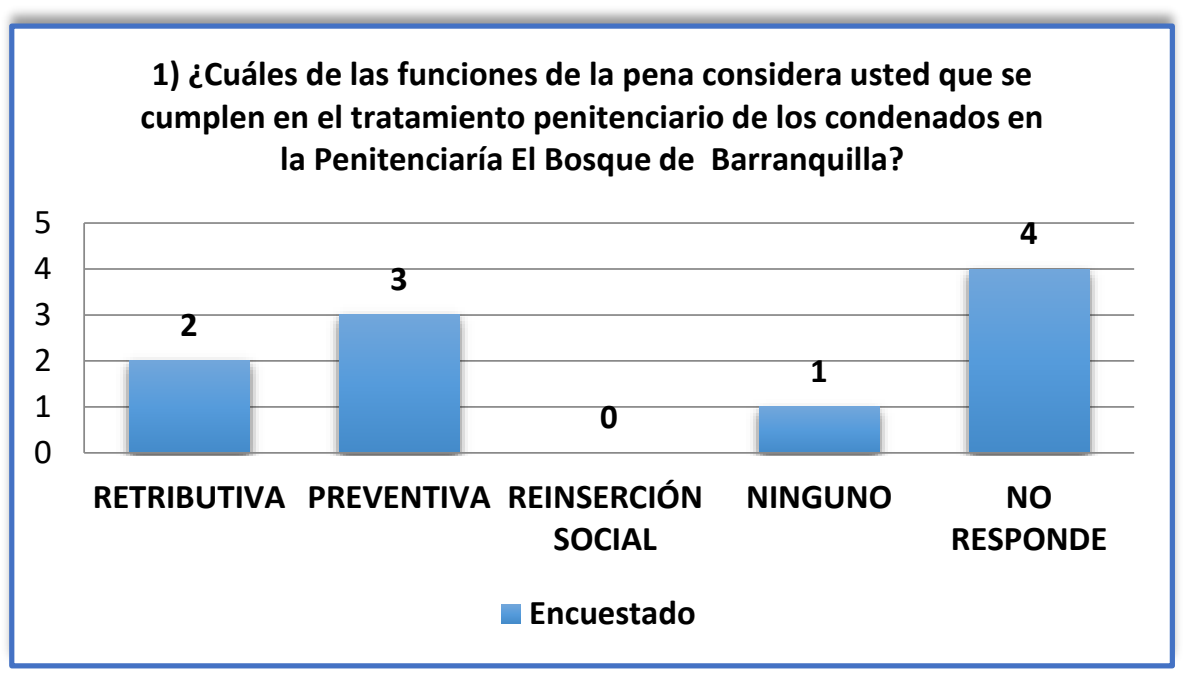

Gráfica 1: Del total de los abogados encuestados, el mayor porcentaje de éstos no responde a la pregunta formulada. Seguidamente con mayor opinión, los abogados encuestados indican que la función de la pena que se cumple en el tratamiento penitenciario que reciben los condenados recluidos en la Penitenciaría El Bosque de la ciudad de Barranquilla es la función preventiva.

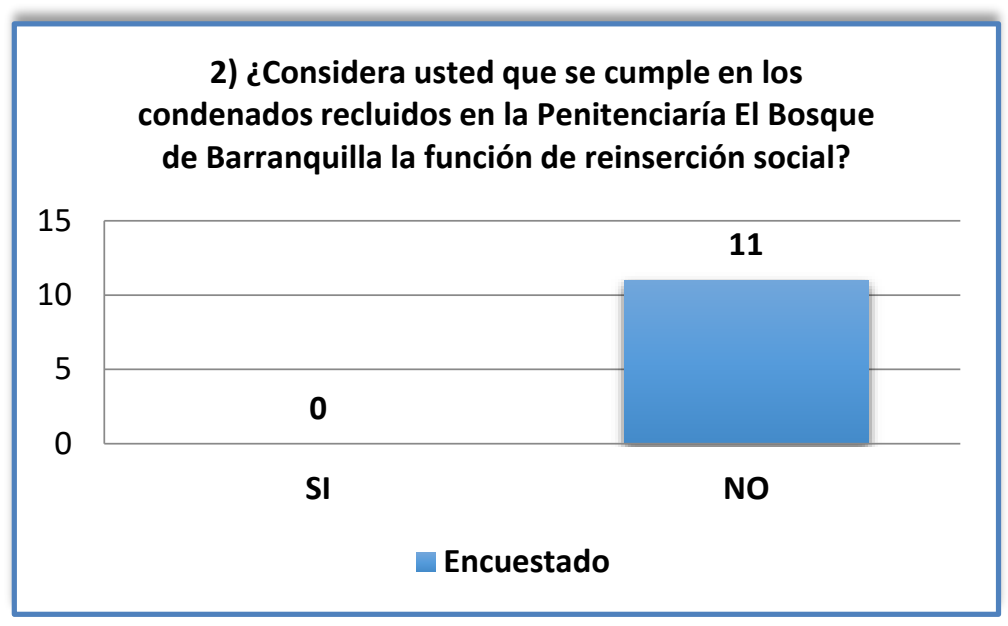

Gráfica 2: Todos los abogados encuestados responden que en la Penitenciaría El Bosque de la ciudad de Barranquilla no se cumple la función de reinserción social en los condenados. 


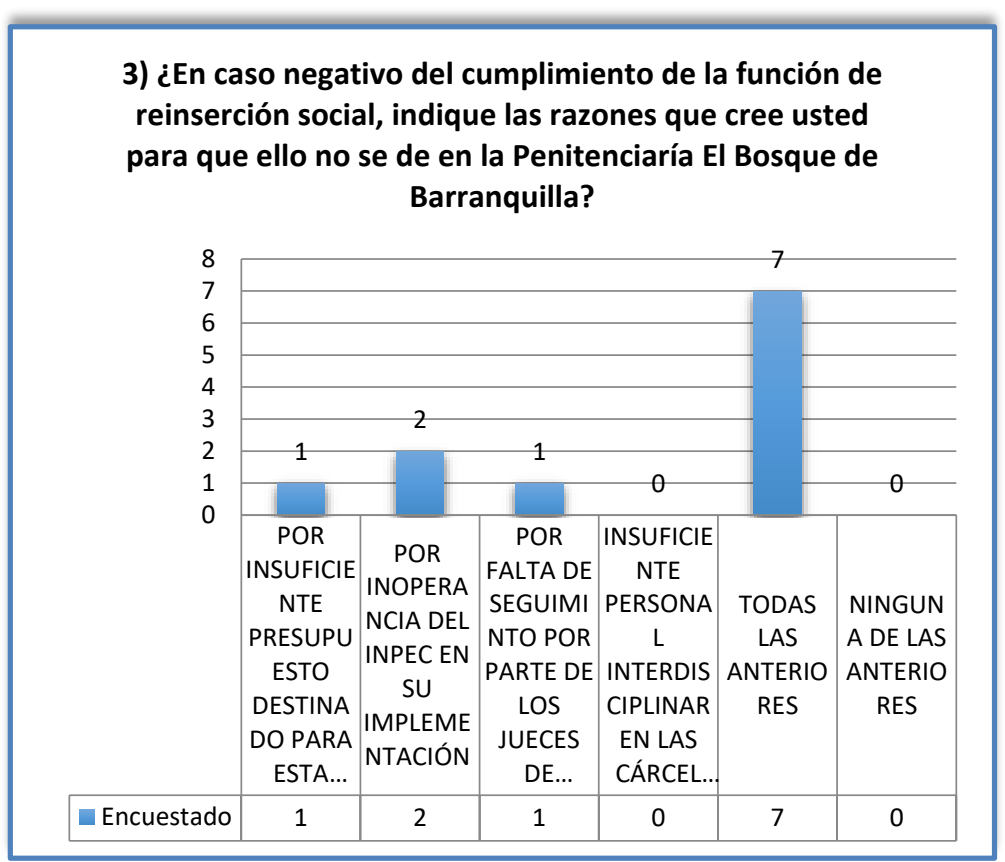

Gráfica 3: Teniendo en cuenta que todos los abogados encuestados respondieron que en los condenados no se cumple la función de reinserción social, se indagó sobre cual considerarían los encuestados es la causa para que esto no se cumpla. De las opciones planteadas la mayoría aseveró que obedece a diferentes causas y por ello pudieron enmarcar sus respuestas, ubicando con mayor opción la de "todas las anteriores". Seguidamente la opción escogida por los abogados encuestados fue la de la inoperancia del INPEC en la implementación de la política de reinserción social al interior de la Penitenciaria el Bosque de Barranquilla.

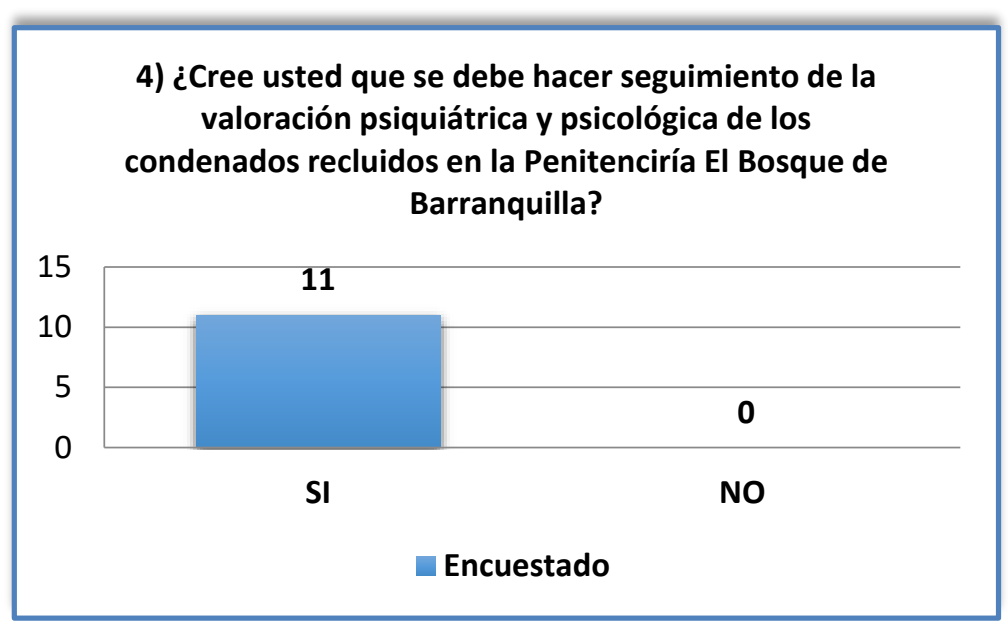


Gráfica 4: Los abogados encuestados afirman que es necesario que los condenados recluidos en la Penitenciaría El Bosque de Barranquilla deben recibir seguimiento luego de la valoración psiquiátrica y psicológica de cada condenado.

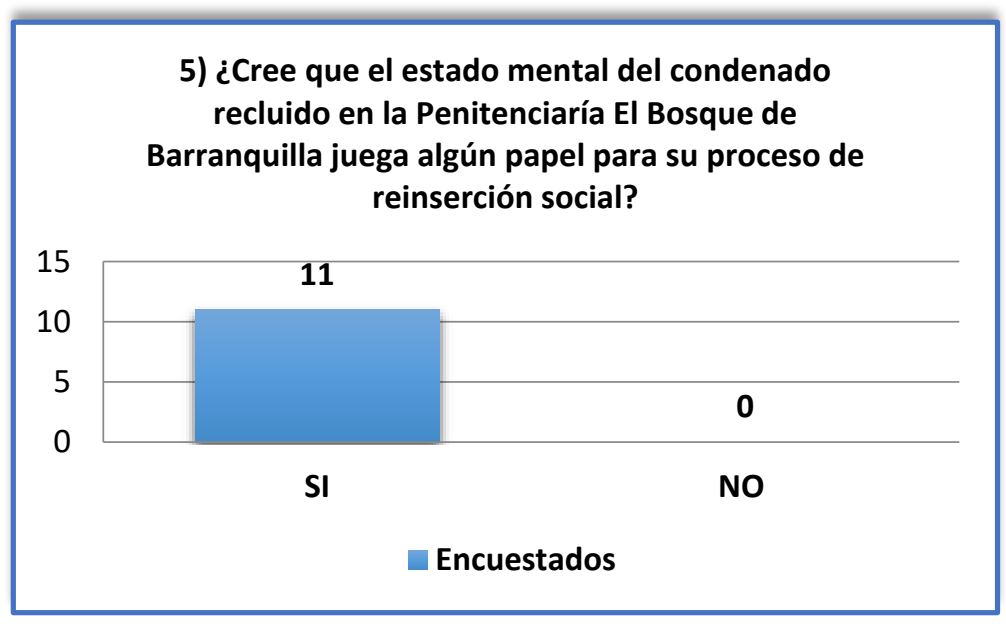

Gráfica 5: Todos los abogados encuestados consideran que el estado mental del condenado recluido en la Penitenciaría El Bosque de Barranquilla influye de manera significativa en su proceso de reinserción social.

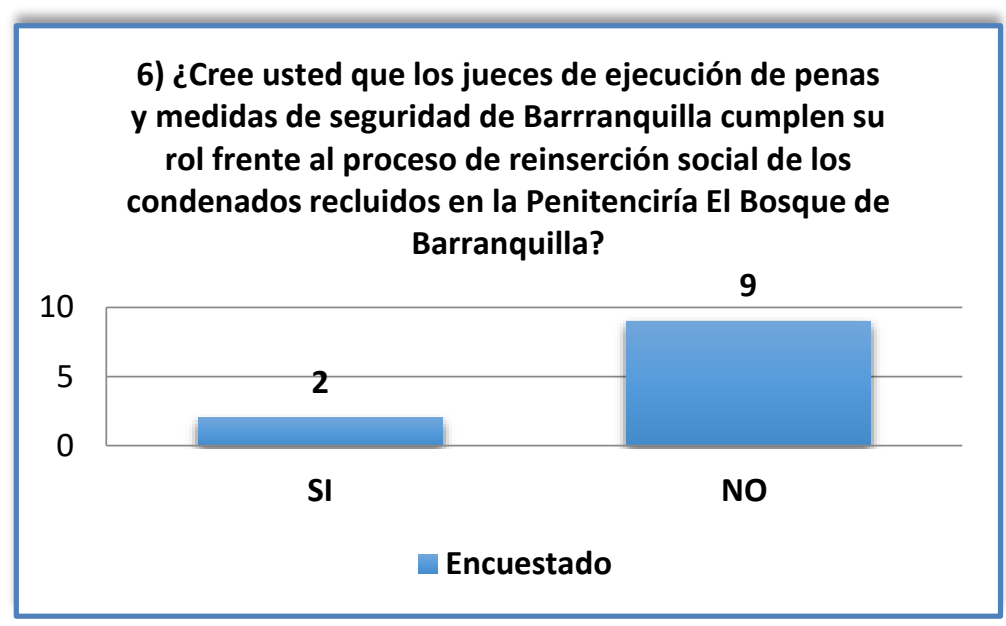

Gráfica 6: En un gran porcentaje, los abogados encuestados consideran que en Barranquilla, los jueces de ejecución de penas y medidas de seguridad no están cumpliendo el rol que les compete en lo que respecta al proceso de reinserción social de los condenados recluidos en la Penitenciaría El Bosque de Barranquilla. 


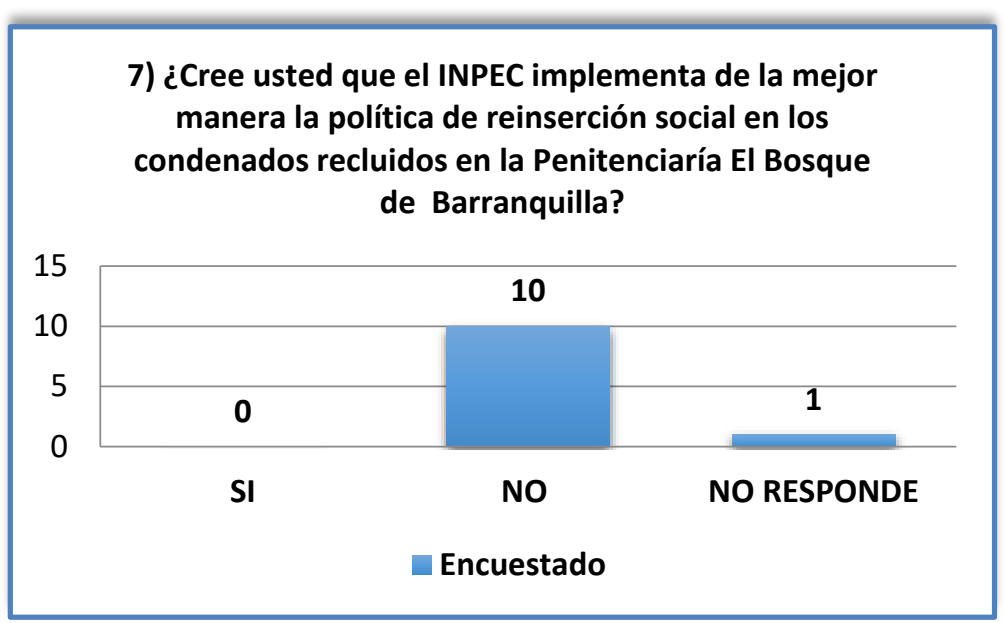

Gráfica 7: Se encontró de acuerdo a lo respondido por la mayoría de los abogados encuestados que la percepción que ellos tienen respecto a la implementación de la política de reinserción social de los condenados recluidos en la Penitenciaría El Bosque de Barranquilla por parte del INPEC no se está dando de manera idónea.

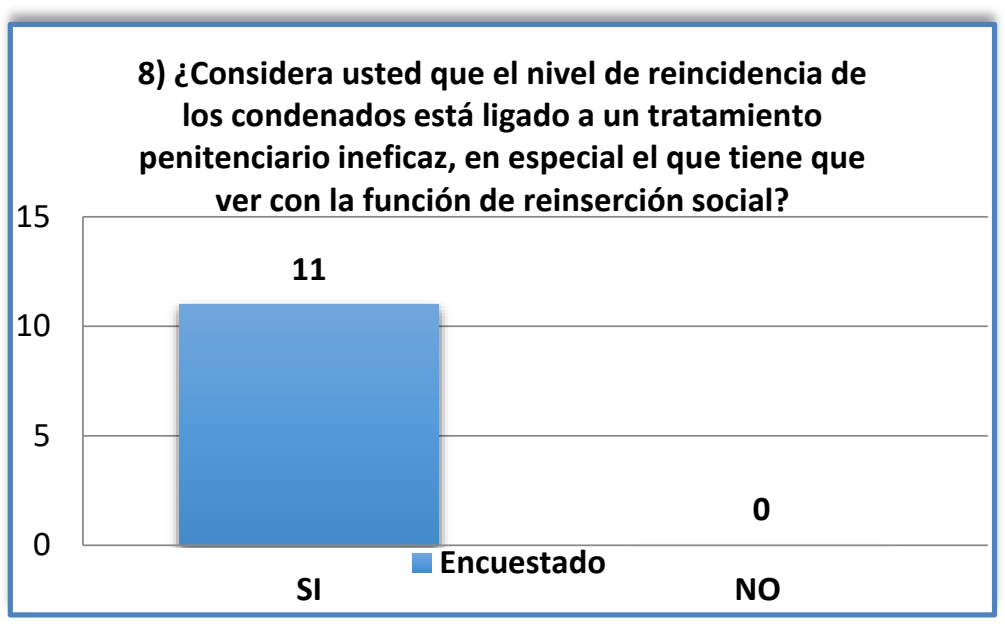

Gráfica 8: Los abogados encuestados consideran que la reincidencia de los condenados obedece a que el tratamiento que éstos reciben al interior del centro carcelario y penitenciario El Bosque no es eficaz, en especial con la función de reinserción social.

De los anteriores resultados arrojados por la encuesta realizada a abogados penalistas de Barranquilla se desprenden varios aspectos, el primero de ellos es el reconocimiento frente al incumplimiento de la función de reinserción social en los condenados recluidos en la Penitenciaría El Bosque de Barranquilla, a lo que entre las razones que exponen para esta situación le atañe al 
papel del INPEC y de los jueces de ejecución de penas y medidas de seguridad de Barranquilla, por un lado por parte de funcionarios del INPEC responsables del proceso educativo, cultural, deportivo, psicológico, productivo, familiar de los condenados al interior del centro de reclusión y por otro lado el papel desarticulado que tienen los jueces de ejecución de penas con quienes deben responder por este proceso indispensable para la consecución de la reinserción social y como consecuencia de ello se ve reflejado en los altos índices de reincidencia en la Penitenciaría El Bosque de Barranquilla.

\section{CONCLUSIONES}

Se puede concluir atendiendo a lo concerniente al papel del juez de ejecución de penas y medidas de seguridad en Colombia, en especial al desarrollado por los de Barranquilla, que de acuerdo a las entrevistas realizadas a tres de ellos se pudo evidenciar el papel pasivo que cumplen y lo más grave aún es que justifican esa pasividad al trasladar al INPEC esa responsabilidad en lo que respecta al seguimiento y vigilancia de la ejecución de la pena y sus funciones, en especial la de reinserción social.

El papel del juez de ejecución de penas y medidas de Seguridad en Barranquilla dentro del proceso de reinserción social en atención a los condenados en la Penitenciaría El Bosque de Barranquilla, reconocen que visitan a los condenados de manera periódica y que el seguimiento lo realizan a través de la percepción que de este proceso le hacen llegar los funcionarios del INPEC a través de sus informes y están convencidos en que la responsabilidad del proceso de reinserción social recae sobre el INPEC en la aplicación del tratamiento penitenciario, por ser éstos lo que a día a día comparten con los internos y ratifican que su rol solo es atender y resolver las solicitudes de los internos con respecto a sus beneficios administrativos y solicitudes de libertad y redención por estudio o trabajo (Trujillo, 2018; Diaz y Vega, 2018).

Cuando se les indaga de como realizan el seguimiento a la función de reinserción social son claros en manifestar que esto es tarea del INPEC y que es en el Consejo de Evaluación y tratamiento cuando mediante actas se pone en conocimiento del proceso llevado por cada condenado a efecto de decidir sobre algún pedimento de los condenados.

Por tanto es el INPEC, a juicio de los jueces de ejecución de penas y medidas de seguridad, el responsable de que el proceso de reinserción social sea eficaz o fracase, siendo esto último lo que acontece y según lo expresado por los jueces obedece al hacinamiento carcelario, desorden corrupción, falta de presupuesto, mala infraestructura de las cárceles, pocos cupos para que los condenados reciban en su totalidad el tratamiento penitenciario, situación que se evidencia en la desarticulación que existe entre la política carcelaria y penitenciaria de nuestro país.

Situación que es corroborada con las entrevistas a los condenados quienes al unísono contestaron en sus respuestas la poca atención que estos jueces prestan al desarrollo de su proceso de ejecución de la pena ya que con poca frecuencia los ven y si van a la Penitenciaría solo se acercan a la oficina jurídica, lo que demuestra que es poco el contacto directo que tienen con los condenados por tanto no pueden percibir la manera como se desarrolla el cumplimiento de las funciones de la pena. Además de la demora de los jueces en resolver sus peticiones.

Estos resultados arrojados en este objetivo permiten concluir que es preciso enrumbar las políticas de tratamiento penitenciario hacia el verdadero cumplimiento de las funciones de la pena 
que le permitan al condenado recibir un trato digno y a su vez en caso de requerirlo seguimiento y control psicoterapéutico a fin de prevenir la reincidencia que demuestra cada día más que la pena así como es aplicada no está cumpliendo con el espíritu verdadero de la misma y que el juez de ejecución de penas y medidas de seguridad debe asumir el papel protagónico en este proceso, ya que su papel se está limitando a resolver asuntos relacionados con beneficios administrativos de los condenados olvidándose que debe aportar su grano de arena a mejorar al ser humano que cometió un delito, esa es la función social de este juez.

La realidad que se pudo percibir en la Penitenciaría El Bosque de Barranquilla expresa que si bien hoy existen los Jueces de Ejecución de Penas y Medidas de Seguridad en el país, es para que cumplan un rol activo en el proceso de reinserción social y pareciere que interpretaran sus funciones de manera aislada a este proceso que lo comprenden como una etapa posterior al cumplimiento de la pena, pero la recomendación es sensibilizar a los jueces que tienen este rol, de la importancia de la reinserción social, y su aporte para que cada condenado la consiga con apoyo especialistas de distintas disciplinas y funcionarios del INPEC y con apoyo también de entidades gubernamentales del orden nacional que le apuesten con presupuesto para que esto se pueda lograr. Donde la academia, los investigadores también tengan participación activa.

Tener un número considerable de jueces de ejecución de penas para que puedan cumplir a cabalidad la función de reinserción social, ya que es la manera como se acaba con la reincidencia. Por ello se destaca la vigilancia permanente que deben mantener estos jueces respecto de los derechos fundamentales dentro de los Establecimientos Carcelarios, pero estos funcionarios no visitan los establecimientos carcelarios, lo que demuestra un incumplimiento de dicha función, y la causa principal de esto es el factor tiempo, según ellos.

Frente a la poca atención que le prestan los jueces de ejecución de penas al cumplimiento de esta función viene dada por la vulneración de Derechos Fundamentales en las penitenciarías, la supuesta existencia de otros organismos para desempeñar ésta función, como son las mesas de trabajo de dichos establecimientos o esperar que dichas afecciones a Derechos Fundamentales sean resueltas por otros Jueces a través del mecanismo de la acción de tutela y Frente al hacinamiento carcelario, la aceptación tácita (casi expresa) que el Estado no tiene recursos ni presupuesto para crear ni construir más cárceles.

Se considera que los Jueces de Ejecución de Penas y Medidas de Seguridad, son un instrumento legal válido y están inspirados en una filosofía de desarrollo de garantías en la etapa de ejecución penal, pero no desarrollan todas las funciones asignadas en su totalidad, especialmente aquellas que los haría verdaderos jueces de garantía con respecto a la ejecución de la sentencia.

Falla el Estado en cuanto a la distribución de estos Jueces que solo tienen asentamiento en las ciudades capitales y con competencia en todo un Departamento, incluyendo cárceles de distrito, así como todas las municipales en los lugares más alejados de la geografía del país, aspecto manifestado en las entrevistas realizadas a los mismos.

Los condenados a penas de prisión, son seres humanos que tienen sus derechos vigentes y por lo tanto se requiere una intervención urgente para esta situación tan grave en los establecimientos carcelarios y penitenciarios, donde lo único que se observa es una vulneración reiterada de Derechos Fundamentales, en la que el Estado tiene una gran responsabilidad, pero también estos jueces que actúan más en procesos administrativos que en procesos que garanticen los derechos fundamentales. En voz de los condenados a quienes se les preguntó sobre las sugerencias para mejorar el proceso de reinserción social, donde son ellos los protagonistas respondieron por parte del INPEC más apoyo para el desarrollo de actividades realizadas por personal especializado y de 
distintas disciplinas; más actividades artísticas, laborales y educativas; más actividades que involucren a sus núcleos familiares; más apoyo psicológico y espiritual; más apoyo legal y celeridad para que los jueces de ejecución de penas respondan a sus solicitudes; que se les enseñen más artes; y que luego de cumplir su pena puedan recibir apoyo para la reinserción laboral y no ser rechazados o estigmatizados por el hecho de haber estado privados de su libertad.

Nadie se explica cómo en Colombia y otros países de Latinoamérica, existiendo este tipo de jueces exclusivamente para la verificación de la etapa de ejecución penal, existan cárceles con un hacinamiento superior al $100 \%$, que las condiciones de las cárceles sean deplorables y que a menudo se sucedan revueltas, motines y desordenes en los que mueren internos con la complicidad pasiva de quienes fueron creados precisamente para obrar como órgano de protección.

\section{REFERENCIAS.}

Colombia. Código de Procedimiento Penal

Colombia. Código Penitenciario y Carcelario. Reformado por la Ley 65 de 1993

Colombia. Constitución Nacional de 1991

Colombia. Corte Suprema de Justicia. Sala Penal. Auto AP-83122016 (49271), Nov. 30/16.

Díaz, R. \& Vega, J. (2018). La introducción de resultados científicos historiográficos de historia local: una contribución a la formación profesional pedagógica. Amauta, 16(31), 189203. http://dx.doi.org/10.15648/am.31.2018.11

Entrevistas a Jueces de Ejecución de Penas y Medidas de Seguridad de Barranquilla.

Encuestas a Abogados penalistas de Barranquilla.

https://www.quadratin.com.mx/sucesos/Funcion-del-juez-de-ejecucion-de-sanciones-en-NuevoSistema-de-Justicia/

http://www.terragnijurista.com.ar/doctrina/juez.htm

http://m.monografias.com/trabajos29/juez-ejecucion-penal/juez-ejecucion-penal.shtml.

Guzmán, P. (2014) El incesto desde la perspectiva psicojurídica. Una mirada holística del delito para un tratamiento penitenciario eficaz. Editorial Universidad Simón Bolívar. Colombia Barranquilla.

Rodríguez, F; Hernández \& Tuirán. (2010). La valoración racional de la prueba en el derecho penal. En: Estudios contemporáneo del Derecho Penal. Barranquilla. Edición Universidad Simón Bolívar. 
Rodríguez, F y Guzmán, P. (2009). La eficacia de la prueba de ADN en el esclarecimiento de delitos en Barranquilla. En: La investigación jurídica y sociojuridica en Colombia: Avances y resultados de investigación. Compiladores: Carlos Mario Molina Betancur. IX Encuentro de la red de grupos y centros de investigación jurídica y sociojuridica. Cali. Edición Pontificia Universidad Javeriana, Asociación de facultades de derecho. ACOFADE, y Universidad de San Buenaventura.

Trujillo Culebro, F. (2018). La didáctica de la literatura en secundaria. Amauta, 16(32), 49-68. https://doi.org/10.15648/am.32.2018.4 
La función de reinserción social y el papel de los jueces de ejecución de penas y medidas de seguridad en

\section{Patricia Guzman González}

Abogada de la Universidad del Atlántico. Especialista en Pedagogía de las Ciencias de la Universidad Simón Bolívar. Magister en Derecho Procesal de la Universidad de Medellín. Investigador Asociado de Colciencias. Investigadora Tiempo Completo de la Corporación Universitaria del Caribe Cecar. CORREO

\section{Jaime Rambao Hernández}

Abogado de la Universidad Simón Bolívar. Candidato a magister en Derecho Procesal de la Universidad Simón Bolívar. Coordinador Académico de la Facultad de Derecho y Ciencias Políticas de Cecar. Docente del Programa de Derecho de la Corporación Universitaria del Caribe Cecar. CORREO 